\title{
Analysis of clinical and pathological features of primary bilateral macronodular adrenocortical hyperplasia compared with unilateral cortisol-secreting adrenal adenoma
}

\author{
Qian Zhang ${ }^{1 \#}$, Haiying Xiao"\#, Ling Zhao ${ }^{3}$, Yijun Li $^{4}$, Kang Chen ${ }^{4}$, Li Zang ${ }^{4}$, Jin Du ${ }^{4}$, Xianling Wang ${ }^{4}$, \\ Qinghua Guo ${ }^{4}$, Guoqing Yang ${ }^{2}$, Jianming $\mathrm{Ba}^{4}$, Weijun $\mathrm{Gu}^{4}$, Zhaohui Lyu ${ }^{4}$, Jingtao Dou ${ }^{4}$, Yiming $\mathrm{Mu}^{4}$, \\ Juming $\mathrm{Lu}^{4}$ \\ ${ }^{1}$ Department of Endocrinology, the Seventh Medical Center of Chinese PLA General Hospital, Beijing, China; ${ }^{2}$ Department of Endocrinology, \\ Hainan Hospital of Chinese PLA General Hospital, Sanya, China; ${ }^{3}$ Department of Endocrinology, The 940th Hospital of Joint Logistics Support \\ Force of Chinese PLA, Lanzhou, China; ${ }^{4}$ Department of Endocrinology, the First Medical Center of Chinese PLA General Hospital, Beijing, \\ China \\ Contributions: (I) Conception and design: Q Zhang, J Lu; (II) Administrative support: J Dou, Y Mu; (III) Provision of study materials or patients: \\ H Xiao, S Han, Y Li, K Chen; (IV) Collection and assembly of data: L Zang, J Du, X Wang, Q Guo, G Yang; (V) Data analysis and interpretation: \\ Q Zhang, J Ba, W Gu, Z Lyu; (VI) Manuscript writing: All authors; (VII) Final approval of manuscript: All authors. \\ \#These authors contributed equally to this work. \\ Correspondence to: Jingtao Dou. Department of Endocrinology, the First Medical Center of Chinese PLA General Hospital, Haidian District, Beijing, \\ China. Email: jingtaodou@sohu.com.
}

Background: Primary bilateral macronodular adrenocortical hyperplasia (PBMAH) is a rare condition with untypical subclinical symptoms of Cushing's syndrome (CS). This study aimed to compare the clinical and pathological features of PBMAH with unilateral cortisol-secreting adrenal adenoma (UAA).

Methods: We prospectively included 46 PBMAH patients and 205 UAA patients from January 2000 to February 2014. Cortisol levels and 24 hours urine free cortisol (UFC) were determined at baseline and during dexamethasone suppression test (DST) using the chemiluminescence method. Computed tomography (CT) examination of the adrenal glands was performed in all patients. For patients treated with adrenalectomy, hematoxylin, and eosin, staining was performed for pathological examination.

Results: The proportion of patients with autonomous cortisol secretion was significantly higher in PBMAH patients (39.1\%) than UAA patients (6.8\%). The PBMAH patients showed significantly lower levels of basal cortisol, low dose dexamethasone suppressed cortisol, and high dose dexamethasone suppressed cortisol than the UAA patients $(452.6 \pm 183.3$ vs. $578.7 \pm 166.4 \mathrm{nmol} / \mathrm{L}, \mathrm{P}=0.003 ; 394.5 \pm 298.9$ vs. $549.2 \pm 217.7 \mathrm{nmol} / \mathrm{L}, \mathrm{P}=0.002 ; 397.3 \pm 282.3$ vs. $544.3 \pm 187.6 \mathrm{nmol} / \mathrm{L}, \mathrm{P}=0.003)$. Similarly, the $\mathrm{PBMAH}$ patients had significantly lower levels of basal 24 hours UFC, low dose dexamethasone suppressed 24 hours UFC, and high dose dexamethasone suppressed 24 hours UFC than the UAA patients $(1,144.4 \pm 1,048.1$ vs. $1,674.9 \pm 1,520.4 \mathrm{nmol} / 24 \mathrm{~h}, \mathrm{P}=0.032 ; 1,157.3 \pm 1,483.5$ vs. $1,940.1 \pm 1,360.9 \mathrm{nmol} / 24 \mathrm{~h}, \mathrm{P}=0.003$; $1,256.4 \pm 1,767.0$ vs. $1,969.9 \pm 1,361.7 \mathrm{nmol} / 24 \mathrm{~h}, \mathrm{P}=0.011)$.

Conclusions: $\mathrm{PBMAH}$ is often associated with atypical CS symptoms. The clinical and imaging features of PBMAH are useful for the differential diagnosis of this disease.

Keywords: Cushing's syndrome (CS); computed tomography; hypercortisolism; dexamethasone suppression test (DST); urine free cortisol (UFC)

Submitted Jul 19, 2020. Accepted for publication Sep 11, 2020.

doi: $10.21037 / \mathrm{atm}-20-5963$

View this article at: http://dx.doi.org/10.21037/atm-20-5963

(c) Annals of Translational Medicine. All rights reserved. 


\section{Introduction}

Endogenous Cushing's syndrome (CS) is caused by the primary adrenal over-secretion of cortisol in approximately $15-20 \%$ of the cases (1). Unilateral adrenal adenomas or carcinomas can explain most adrenal CS. However, bilateral lesions handle about $10-15 \%$ of adrenal CS. They include primary pigmented nodular adrenocortical disease (PPNAD), primary bilateral macronodular adrenocortical hyperplasia (PBMAH), and rarely bilateral adenomas or carcinomas (1). PBMAH accounts for less than $1 \%$ of endogenous CS and is often associated with autonomous cortisol secretion (2). PBMAH is usually diagnosed according to the clinical symptoms of CS, demonstration of adrenocorticotropic hormone (ACTH)-independent hypercortisolism, and bilateral adrenal nodular enlargement on computed tomography (CT) images. However, diagnosis of PBMAH is often tricky because hypercortisolism usually develops slowly, and the CS symptoms may take several years to unfold fully (3). Many patients with PBMAH are found incidentally by radiologic imaging. CT and magnetic resonance imaging (MRI) are helpful diagnostic tools but lack specificity (4). The diagnosis of $\mathrm{PBMAH}$ is often challenging and often delayed, leading to inferior treatment outcomes and quality of life of patients.

The specific mechanisms of PBMAH are still not precise. In the past, PBMAH was called ACTH-independent bilateral macronodular adrenal hyperplasia (AIMAH). The cortisol production is stimulated in AIMAH, although the ACTH level is low. Bilateral adrenalectomy in AIMAH patients does not result in ACTH-producing pituitary adenoma or Nelson's syndrome, also suggesting that the cortisol production is ACTH-independent, which was previously considered 'autonomous.' However, recent studies re-examined their pathological mechanisms. They overturned the collective knowledge of its etiology and pathogenesis over the years; the increase in cortisol secretion relied on the secretion of the adrenal tissue itself, and AIMAH should be redefined as "Primary Bilateral Macronodular Adrenal Hyperplasia (PBMAH)" (5-7), which strongly suggested we need to re-examine the hormone secretion characteristics of PBMAH from the clinical view.

Once considered a rare disease, PBMAH is now met with increasing frequency mainly due to the incidental detection of clinically mild or asymptomatic cases during abdominal imaging performed for unrelated reasons. Unilateral cortisol-secreting adrenal adenoma (UAA) accounts for $18-20 \%$ of primary adrenal CS cases, which is well-known.
On the contrary, the insight of PBMAH is still limited. This study aims to improve the recognition of PBMAH by comparing the hormone levels and clinical characteristics with the UAA group. We present the following article in accordance with the MDAR reporting checklist (available at http://dx.doi.org/10.21037/atm-20-5963).

\section{Methods}

\section{Patients}

From January 2000 to February 2014, we prospectively included 46 PBMAH patients and 205 unilateral cortisolsecreting adrenal adenoma patients. $\mathrm{PBMAH}$ was diagnosed according to the following criteria: (I) CS symptoms and signs including moon face, central obesity, thinning of the skin, hypertension, and osteoporosis; (II) bilateral macronodular adrenal hyperplasia showed by CT; (III) if available, surgical pathology shows macronodular adrenal hyperplasia; (IV) exclusion of PPNAD, Cushing's disease or other diseases associated with bilateral adrenocortical hyperplasia. UAA was diagnosed with the following criteria: (I) CS symptoms and signs; (II) unilateral adrenal hyperplasia showed by CT; (III) adrenocortical adenoma showed by pathological examination; (IV) exclusion of other diseases associated with unilateral adrenocortical hyperplasia. The ethics committee of our hospital approved this study (No. 2020062). Informed consent was obtained from all the patients. All procedures performed in this study involving human participants were in accordance with the Declaration of Helsinki (as revised in 2013).

\section{Baseline hormone levels}

Plasma levels of cortisol (midnight, 8 AM, 4 PM), ACTH (midnight, $8 \mathrm{AM}, 4 \mathrm{PM}$ ), and 24 hours urine free cortisol (UFC) were determined using the chemiluminescence method (Siemens, Germany). The standard reference ranges of cortisol at $8 \mathrm{AM}, 4 \mathrm{PM}$, and midnight are 198.7 to $797.5 \mathrm{nmol} / \mathrm{L}, 85.3$ to $459.6 \mathrm{nmol} / \mathrm{L}$, and 0 to $165.7 \mathrm{nmol} / \mathrm{L}$. The normal reference range of ACTH at $8 \mathrm{AM}, 4 \mathrm{PM}$, and midnight is $<10.12 \mathrm{pmol} / \mathrm{L}$. The normal reference range of 24 hours UFC is 98.0 to $500.1 \mathrm{nmol} / 24 \mathrm{~h}$.

Blood samples of 4 patients with UAA and 14 patients with PBMAH were taken every 2 hours during 24 hours for assessment of plasma ACTH and cortisol concentrations. This exploratory hormone level monitoring can help further compare the 24-hour ACTH and cortisol rhythms 
between the two groups.

\section{Dexamethasone testing}

For midnight dexamethasone suppression test (DST), $1 \mathrm{mg}$ dexamethasone was orally administered at midnight. Plasma levels of cortisol were measured at $8 \mathrm{AM}$ on the test day (baseline) and the second day (suppressed). For low dose dexamethasone suppression test (LDDST), $0.5 \mathrm{mg}$ dexamethasone was orally administered every 6 hours for 48 hours. Plasma cortisol levels were measured at $8 \mathrm{AM}$ on the previous day (baseline) and the third day (suppressed). Twenty-four hours UFC was measured on the previous day (baseline) and the second day (suppressed). For high dose dexamethasone suppression test (HDDST), $2 \mathrm{mg}$ dexamethasone was orally administered every 6 hours for 48 hours. The same protocol was used for the measurement of cortisol and 24 hours UFC.

\section{Criteria for autonomous cortisol secretion}

Autonomous cortisol secretion was excluded in patients whose cortisol level was less than $50 \mathrm{nmol} / \mathrm{L}$ after $1 \mathrm{mg}$ DST and was diagnosed in patients whose cortisol level was more than $138 \mathrm{nmol} / \mathrm{L}$ after $1 \mathrm{mg}$ DST. LDDST was further performed if the suppressed serum cortisol level was between 50 and $138 \mathrm{nmol} / \mathrm{L}$. The result supported autonomous cortisol secretion if the LDDST suppressed cortisol level $\geq 50 \mathrm{nmol} / \mathrm{L}$. It shows overt CS when the serum cortisol level is more than $50 \%$ of the base value after HDDST.

\section{Statistical analysis}

Continuous data were represented as mean \pm standard deviation or median (interquartile range). Categorical data were represented as percentages. The comparison was performed using student $t$-test, rank-sum test, or Fisher's exact test when proper. All statistical analysis was performed using SPSS 19.0 software (SPSS, IL, USA). A P value of less than 0.05 is considered statistically significant.

\section{Results}

\section{Basic information}

Patients with UAA were female dominant, while the PBMAH patients showed a more balanced sex ratio. Patients with $\mathrm{PBMAH}$ had significantly higher ages $(\mathrm{P}=0.024)$ and longer disease courses $(\mathrm{P}=0.009)$ than those with unilateral adenoma, suggesting the delayed diagnosis in $\mathrm{PBMAH}$ patients. A significantly higher proportion of autonomous cortisol secretion was found in PBMAH patients (39.1\%) than the unilateral adenoma patients $(6.8 \%)$. The two groups of patients did not differ significantly in most of the clinical features except the moon face $(\mathrm{P}=0.037)$ and central obesity $(\mathrm{P}=0.004)$ (Table 1). Analysis of the reasons for seeking medical advice in PBMAH group were as follows: $24(52.2 \%)$ patients were incidentally found with bilateral macronodular adrenal hyperplasia, $14(30.4 \%)$ patients presented with hypertension, and $8(17.4 \%)$ patients presented with moon face.

\section{Baseline hormone levels}

The PBMAH patients had significantly lower plasma levels of cortisol and 24 hours UFC compared with the unilateral adenoma patients. About $1 / 3(n=16)$ of the PBMAH patients had 8:00 ACTH levels at the lower limit of the normal range. However, most of the patients $(n=196)$ with unilateral adenoma had 8:00 ACTH levels below the lower limit of detection $(1.1 \mathrm{pmol} / \mathrm{L})$ (Table 2).

\section{Cortisol levels and 24 hours UFC during dexamethasone testing}

The PBMAH patients showed significantly lower levels of basal cortisol, LDDST-suppressed cortisol, and HDDSTsuppressed cortisol than the unilateral adenoma patients (452.6 \pm 183.3 vs. $578.7 \pm 166.4 \mathrm{nmol} / \mathrm{L}, \mathrm{P}=0.003 ; 394.5 \pm 298.9$ vs. $549.2 \pm 217.7 \mathrm{nmol} / \mathrm{L}, \mathrm{P}=0.002 ; 397.3 \pm 282.3$ vs. $544.3 \pm 187.6 \mathrm{nmol} / \mathrm{L}, \mathrm{P}=0.003$ ) (Figure $1 A$ ). Similarly, the PBMAH patients had significantly lower levels of basal 24 hours UFC, LDDST-suppressed 24 hours UFC, and HDDST-suppressed 24 hours UFC than the unilateral adenoma patients $(1,144.4 \pm 1,048.1 \mathrm{vs}$. $1,674.9 \pm 1,520.4 \mathrm{nmol} / 24 \mathrm{~h}, \mathrm{P}=0.032 ; 1,157.3 \pm 1,483.5$ vs. $1,940.1 \pm 1,360.9 \mathrm{nmol} / 24 \mathrm{~h}, \mathrm{P}=0.003 ; 1,256.4 \pm 1,767.0$ vs. $1,969.9 \pm 1,361.7 \mathrm{nmol} / 24 \mathrm{~h}, \mathrm{P}=0.011$ ) (Figure $1 B$ ). In the PBMAH patients, both LDDST and HDDST successfully suppressed the cortisol levels $(452.6 \pm 183.3 \mathrm{vs}$. $394.5 \pm 298.9 \mathrm{nmol} / \mathrm{L}, \mathrm{P}<0.001 ; 452.6 \pm 183.3$ vs. $397.3 \pm 282.3 \mathrm{nmol} / \mathrm{L}, \mathrm{P}<0.001)$. However, in patients with UAA, LDDST failed to suppress the cortisol levels (578.7 \pm 166.4 vs. $549.2 \pm 217.7, \mathrm{P}=0.101$ ), while HDDST successfully suppressed the cortisol levels $(578.7 \pm 166.4 \mathrm{vs}$. 
Table 1 Basic information of the PBMAH patients and the unilateral cortisol-secreting adrenal adenoma patients

\begin{tabular}{|c|c|c|c|}
\hline Characteristics & PBMAH $(n=46)$ & Unilateral adenoma $(n=205)$ & $P$ value \\
\hline Age at presentation (year) & $52.1 \pm 8.7$ & $39.2 \pm 11.5$ & 0.0279 \\
\hline Mean disease course (year) & $6.5 \pm 4.0$ & $2.3 \pm 2.1$ & 0.000 \\
\hline Body mass index $\left(\mathrm{kg} / \mathrm{m}^{2}\right)$ & $26.7 \pm 3.9$ & $24.8 \pm 3.8$ & 0.784 \\
\hline \multicolumn{4}{|l|}{ Clinical features } \\
\hline Hypertension & $44(95.7 \%)$ & $174(84.8 \%)$ & 0.014 \\
\hline Hyperglycemia & $35(76.1 \%)$ & $126(61.5 \%)$ & 0.064 \\
\hline Lower limb edema & $6(13.0 \%)$ & $31(15.1 \%)$ & 0.719 \\
\hline Moon face & $14(30.4 \%)$ & $178(87.8 \%)$ & 0.000 \\
\hline Central obesity & $19(41.3 \%)$ & $180(87.8 \%)$ & 0.000 \\
\hline Buffalo hump & $10(21.7 \%)$ & $65(31.7 \%)$ & 0.214 \\
\hline Thinning of the skin & $29(63.0 \%)$ & $170(82.9 \%)$ & 0.008 \\
\hline Subcutaneous hemorrhage & $22(47.8 \%)$ & $125(61.0 \%)$ & 0.104 \\
\hline Dilation of capillaries & $20(43.5 \%)$ & $125(61.0 \%)$ & 0.033 \\
\hline Hirsutism & $11(23.9 \%)$ & 75 (36.7\%) & 0.102 \\
\hline Acne & $5(10.9 \%)$ & $46(22.4 \%)$ & 0.078 \\
\hline
\end{tabular}

PBMAH, primary bilateral macronodular adrenal hyperpalsia; CS, Cushing's syndrome.

Table 2 Baseline hormone levels in the PBMAH patients and the unilateral cortisol-secreting adenoma patients

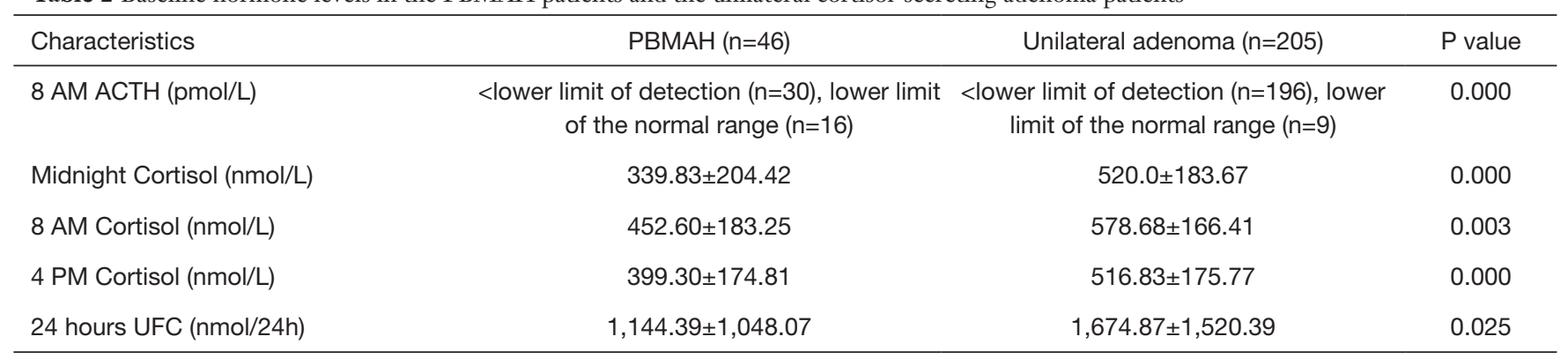

PBMAH, primary bilateral macronodular adrenal hyperpalsia; UFC, urine free cortisol. 

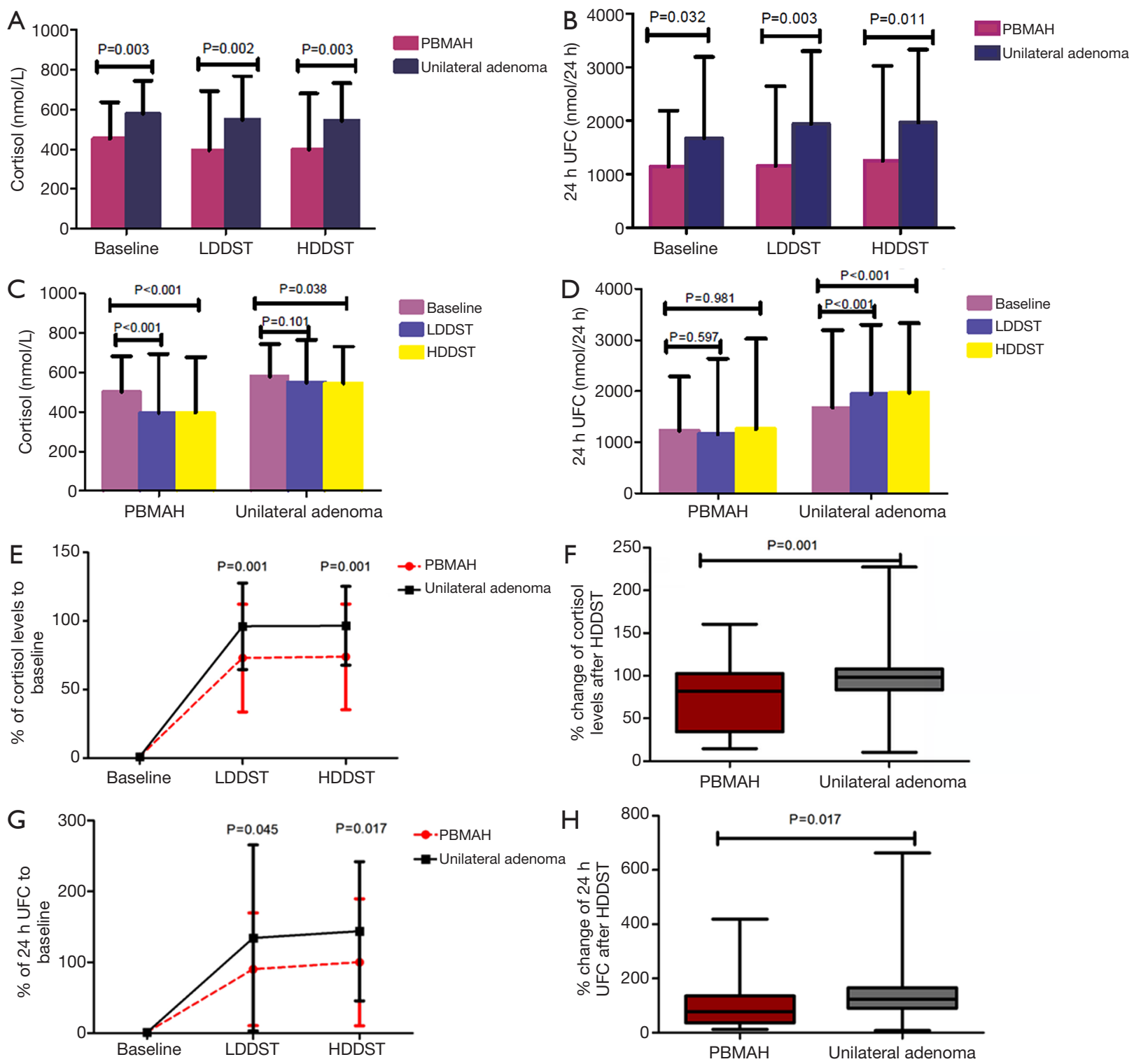

Figure 1 Results of dexamethasone suppression tests. (A) Comparison of cortisol levels between the PBMAH patients and the unilateral adenoma patients. (B) Comparison of 24 hours UFC between the PBMAH patients and the unilateral adenoma patients. (C) Comparison of cortisol levels before and after dexamethasone suppression. (D) Comparison of 24 hours UFC before and after dexamethasone suppression. (E) The percentages of cortisol levels to the baseline after dexamethasone suppression. (F) Comparison of the percent change in cortisol levels between the PBMAH patients and the unilateral adenoma patients after HDDST. (G) The percentages of 24 hours UFC to the baseline after dexamethasone suppression. (H) Comparison of the percent change in 24 hours UFC between the PBMAH patients and the unilateral adenoma patients after HDDST. PBMAH, primary bilateral macronodular adrenal hyperpalsia; UFC, urine free cortisol; HDDST, high dose dexamethasone suppression test.

$544.3 \pm 187.7 \mathrm{nmol} / \mathrm{L}, \mathrm{P}=0.038$ ) (Figure $1 C$ ). No significant change in the 24 hours UFC was noticed in PBMAH patients after dexamethasone test $(1,144.4 \pm 1,048.1 \mathrm{vs}$. $1,157.2 \pm 1,483.51 \mathrm{nmol} / 24 \mathrm{~h}, \mathrm{P}=0.597 ; 1,144.4 \pm 1,048.1$ vs.
$1,256.4 \pm 1,767.0, \mathrm{P}=0.981)$. In the contrary, patients with UAA showed significant changes in the 24 hours UFC after LDDST $(1,674.9 \pm 1,520.4$ vs. $1,940.1 \pm 1,360.9, \mathrm{P}<0.001)$ and $\operatorname{HDDST}(1,674.9 \pm 1,520.4$ vs. $1,969.9 \pm 1,361.7, \mathrm{P}<0.001)$ 

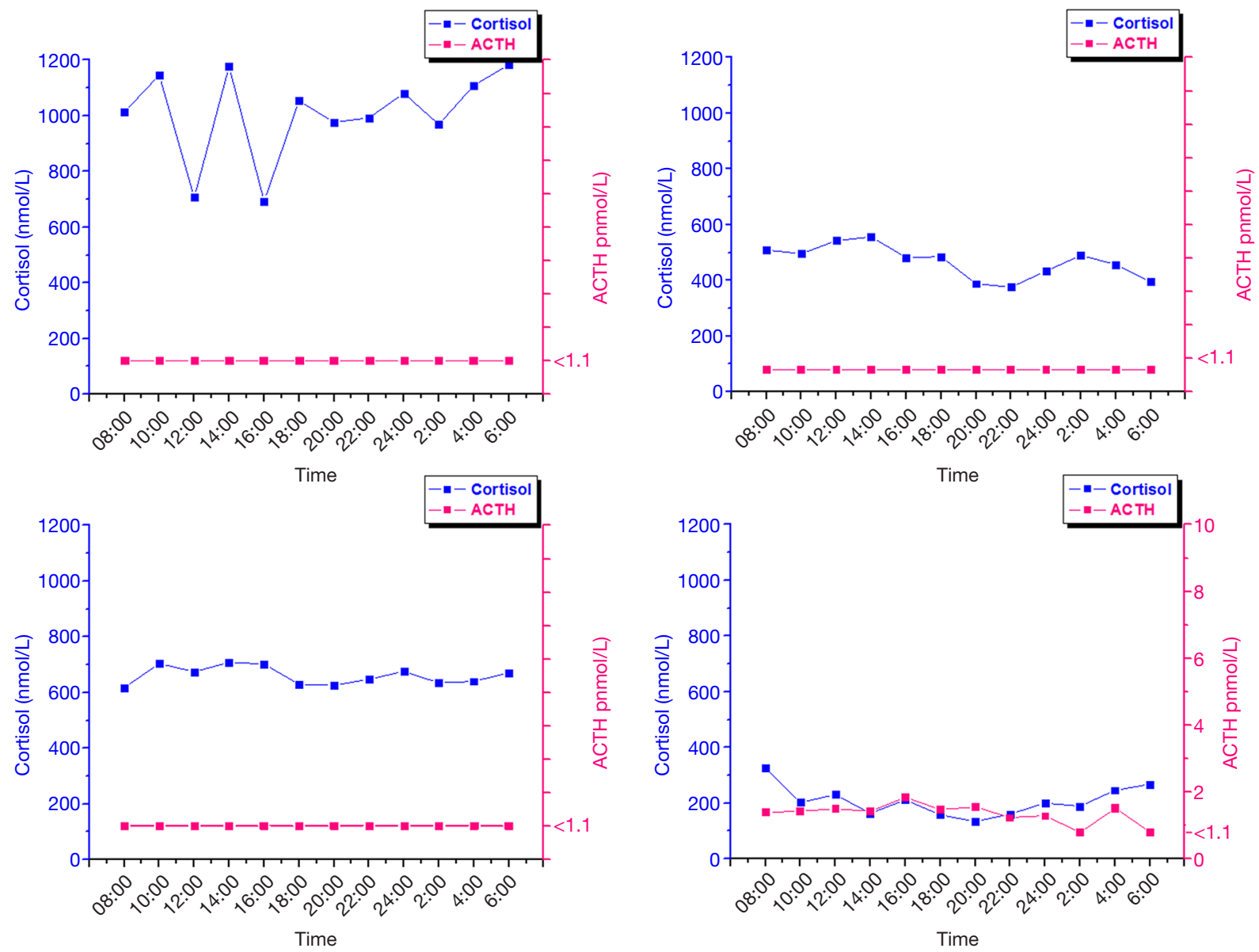

Figure 2 Profiles of 24 hours ACTH and cortisol levels in four patients with UAA. ACTH, adrenocorticotropic hormone; UAA, unilateral cortisol-secreting adrenal adenoma.

(Figure 1D). The percentages of cortisol level to the baseline were significantly lower in the PBMAH patients than the unilateral adenoma patients after LDDST $(73.0 \% \pm 39.3 \%$ vs. $96.1 \% \pm 31.6 \%, \mathrm{P}=0.001)$ and HDDST $(73.9 \% \pm 38.5 \%$ vs. $96.6 \% \pm 28.8 \%, \mathrm{P}=0.001$ ) (Figure $1 E$ ). The percent change in cortisol levels after HDDST was significant higher in the unilateral adenoma patients than the PBMAH patients [median $98.65 \%(86.11 \%, 108.02 \%)$ (interquartile range) vs. median $70.75 \%$ (33.61\%, 102.04\%) (interquartile range), $\mathrm{P}=0.001]$ (Figure $1 F$ ). Similarly, the percentages of 24 hours UFC to the baseline were significantly lower in the PBMAH patients than the unilateral adenoma patients after LDDST $(90.1 \% \pm 79.6 \%$ vs. $134.5 \% \pm 131.3 \%, \mathrm{P}=0.045)$ and HDDST $(100.1 \% \pm 89.6 \%$ vs. $143.8 \% \pm 98.1 \%, \mathrm{P}=0.017$ ) (Figure $1 G$ ). The percent change in 24 hours UFC after HDDST was significant higher in the unilateral adenoma patients than the PBMAH patients [median $147.14 \%$ (91.34\%, $177.34 \%)$ (interquartile range) vs. median
91.58\% (37.54\%, $122.27 \%)$ (interquartile range), $\mathrm{P}=0.017$ ] (Figure 1H).

\section{Twenty-four-hour profile of ACTH and cortisol levels}

The four patients with UAA showed typical clinical features and dexamethasone suppression results of CS. The 24 hours profiles of cortisol levels were enhanced without normal circadian rhythm. The ACTH levels were below the limit of detection (LOD) $(1.1 \mathrm{pmol} / \mathrm{L})$ and showed no association with the cortisol levels (Figure 2). Of the 14 patients with PBMAH, 10 (cases 1-10) were diagnosed with typical $\mathrm{CS}$, and 4 (cases 11-14) were diagnosed with autonomous cortisol secretion after assessment of clinical symptoms and signs and DST. In cases 1 and 2, the ACTH levels were below the LOD, and the cortisol levels were high, but the normal cortisol rhythms disappeared throughout the 
day, showing no differences with the results of four UAA patients with typical CS. In cases 3 and 4, the ACTH levels were below the LOD, and the normal cortisol rhythms disappeared, and the cortisol levels were not increased throughout the day. In cases 7-10, the ACTH levels were at the lower limit of the normal value but not lower than the LOD, the cortisol levels were increased, and the normal cortisol rhythms disappeared throughout the day, showing no association between the cortisol levels and ACTH levels. Of the four autonomous cortisol secretion cases, the ACTH levels were lower than the LOD throughout the day in two cases; in the other two cases, the ACTH levels were at the lower limit of the normal value in some periods but lower than the LOD in some periods throughout the day. The cortisol levels were low but had normal rhythms throughout the day in all the four cases (Figure 3).

\section{CT image features of PBMAH}

All 46 PBMAH patients showed bilateral diffuse macronodular adrenal hyperplasia. The nodules ranged in size from 0.5 to $3.5 \mathrm{~cm}$, with a mean of $1.8 \pm 0.9 \mathrm{~cm}$. In most cases, the adrenal glands still had an standard shape (Figure $4 A, B)$. However, several patients had significant macronodules that had lost the standard shape of the adrenal gland (Figure 4C,D). Uniform enhancement of adrenal tissues was observed on the enhanced scans of 46 patients. The CT attenuation value was in a range of $8-24 \mathrm{Hu}$ (mean $4.58 \pm 6.98$ ) on unenhanced scans and in a range of 22-66 Hu on enhanced scans.

\section{Pathological features of PBMAH}

Gross pathological examination showed diffuse macronodular hyperplasia of the PBMAH. The nodular size ranged from 0.5 to $3.5 \mathrm{~cm}$ (Figure $5 A$ ). The weight of unilateral adrenal gland lesions in the PBMAH group ranged from 40 to $90 \mathrm{~g}$. Microscopic examinations showed diffuse cortical hyperplasia with nodules of many sizes. The nodules consisted of transparent cells and eosinophils. No abnormal mitosis was observed (Figure 5B,C).

\section{Treatment of PBMAH patients}

In the 28 PBMAH patients with overt CS, 6 patients refused surgery and only took medicine for symptomatic treatment due to financial reasons, and 15 patients received adrenalectomy of the larger side. Another 7 patients were first treated with adrenalectomy of the larger side but showed no relief of the symptoms. These patients then received contralateral adrenalectomy and glucocorticoid replacement therapy.

In the 18 PBMAH patients with autonomous cortisol secretion, 11 patients were treated symptomatically with medicine, and 6 patients received adrenalectomy of the larger side. Another patient was first treated with adrenalectomy of the larger side but showed no relief of the symptoms. This patient then received contralateral adrenalectomy and glucocorticoid replacement therapy.

In the patients treated with unilateral adrenalectomy, ten patients (eight with overt CS and two with autonomous cortisol secretion) were followed up by clinic visiting for a mean of 20 months (range, 3-81 months) (Tables 3 and 4). These patients showed significantly lower postoperative systolic pressure, diastolic pressure, 8:00 cortisol, 0:00 cortisol, and 24 hours UFC (Table 5). However, the body mass index and HbA1c level did not change significantly after the surgery. In these patients, the unresected adrenal gland did not change significantly in size in seven patients who were followed up for a short period but enlarged significantly in another three patients who were followed up for an extended period.

In the patients treated with bilateral adrenalectomy, three patients (two with overt CS and one with autonomous cortisol secretion) were followed up by clinic visiting for a mean of 47.7 months (range, 7-88 months) (Tables 6 and 7). The CS was significantly relieved in all three patients after the surgery. One patient was treated with prednisone and adequate salt intake but still had dizziness and fatigue. Further, these symptoms were relieved entirely by added fludrocortisone acetate. The second patient had an adequate hormone supplement and was asymptomatic. The third patient still had symptoms of poor appetite and fatigue due to inadequate hormone supplements.

\section{Discussion}

Several studies have been performed to determine the cortisol and 24 hours of UFC levels in CS and PBMAH via the DST. Zhang et al. discussed the relationship between patients' clinical characteristics, biochemical, endocrinological, and imaging examination results, the therapeutic effects. They found both LDDST and HDDST were not suppressed in PBMAH, PPNAH (primary pigmented nodular adrenocortical hyperplasia), and EAAH (ectopic adrenocorticotropin adrenal hyperplasia) groups. 

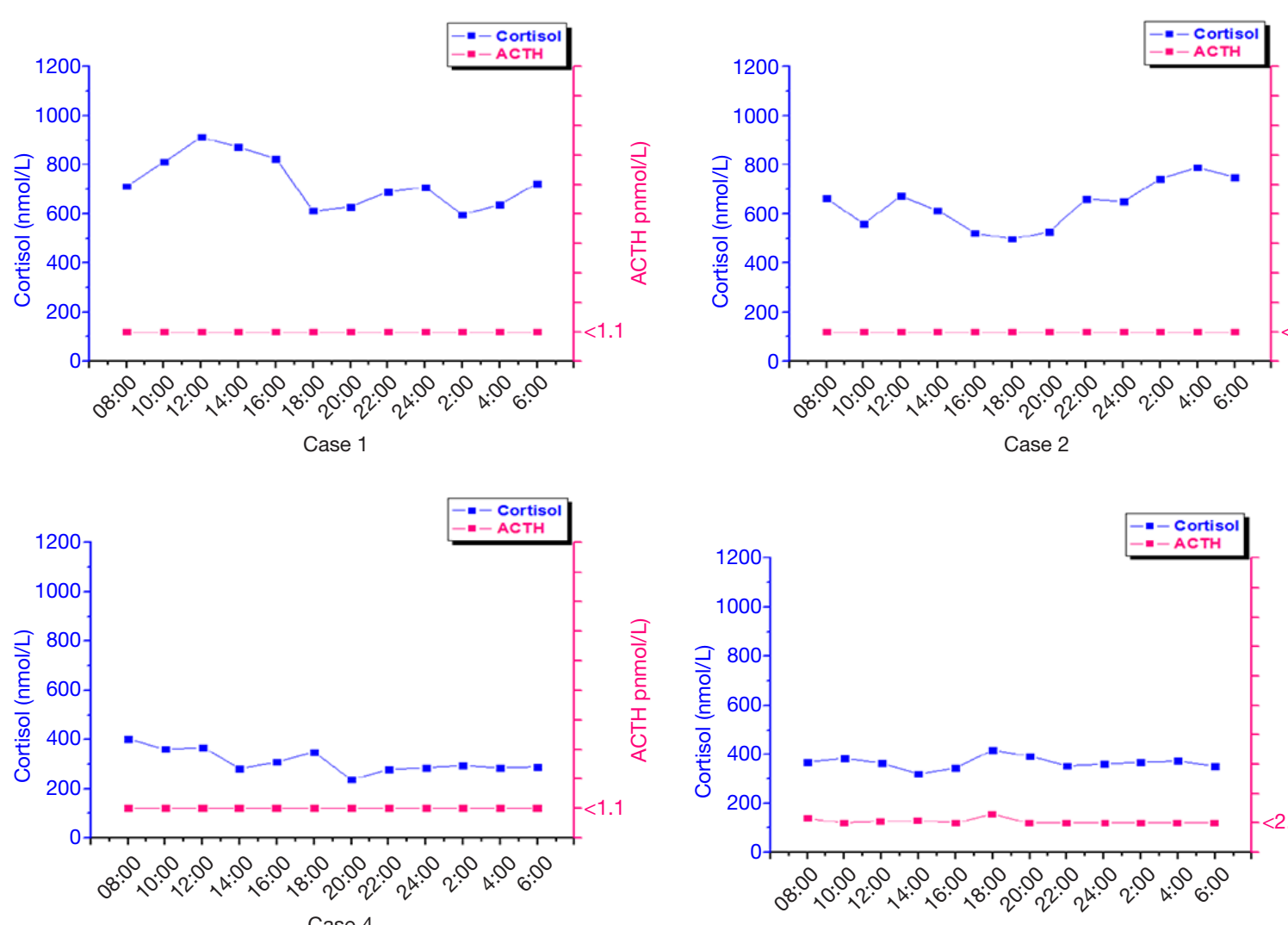

Case 5
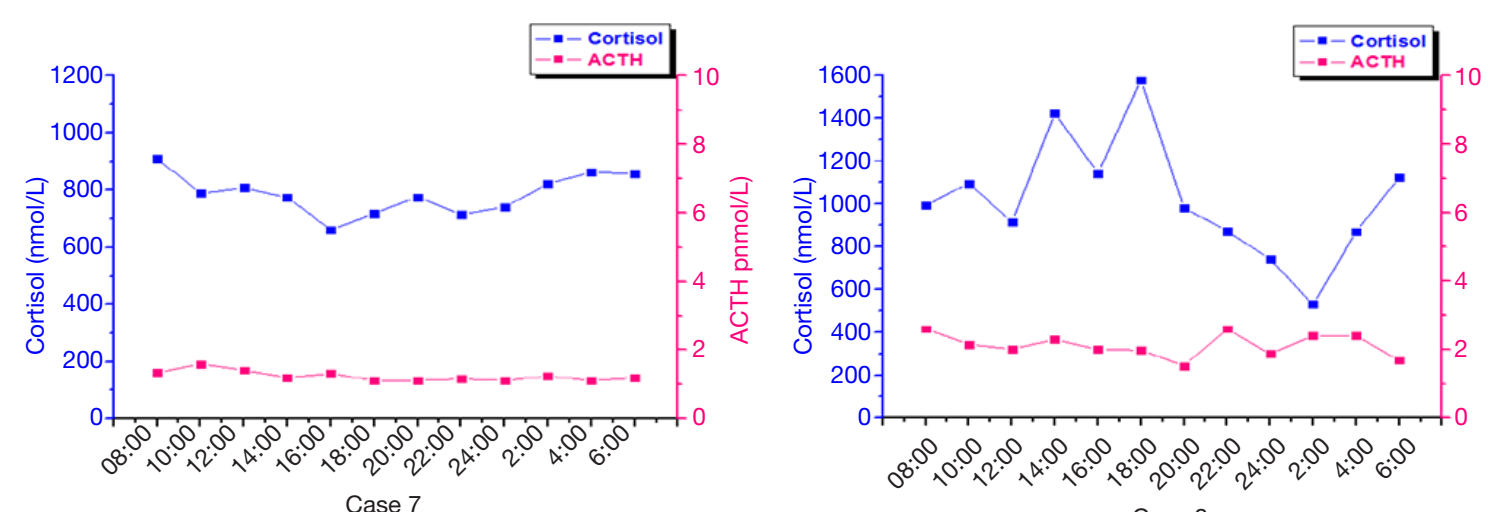
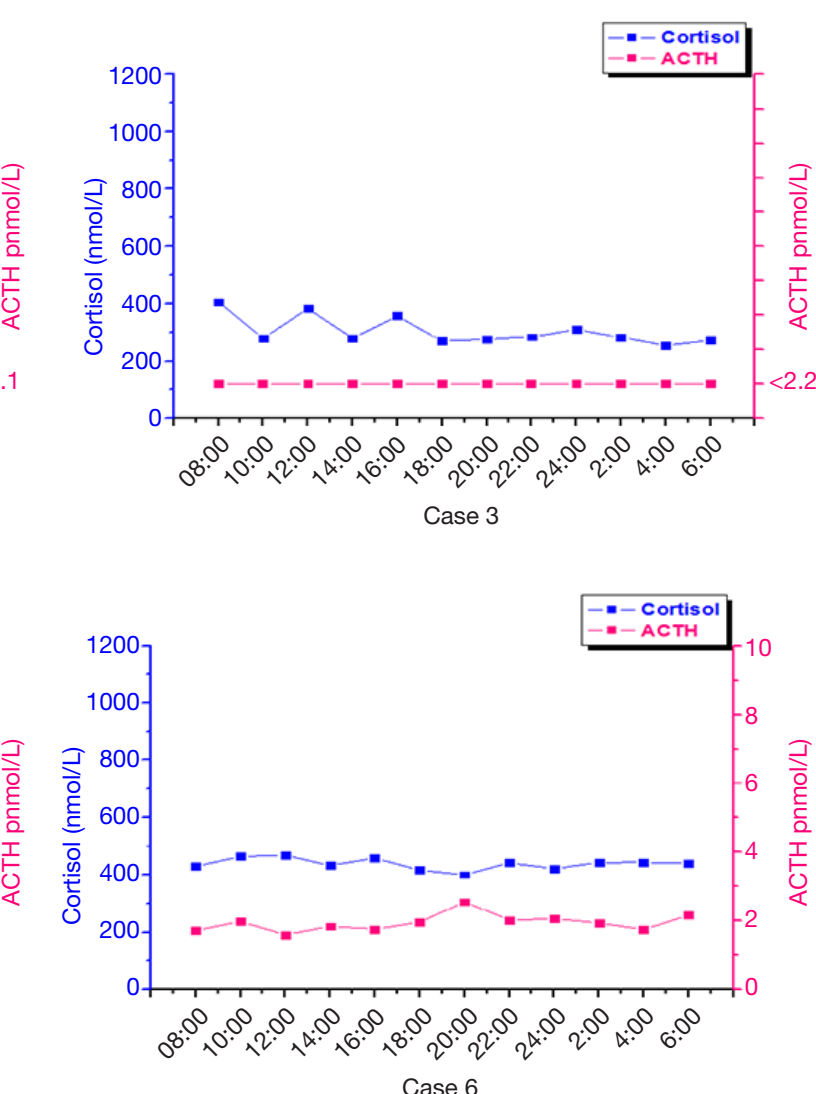

Case 6

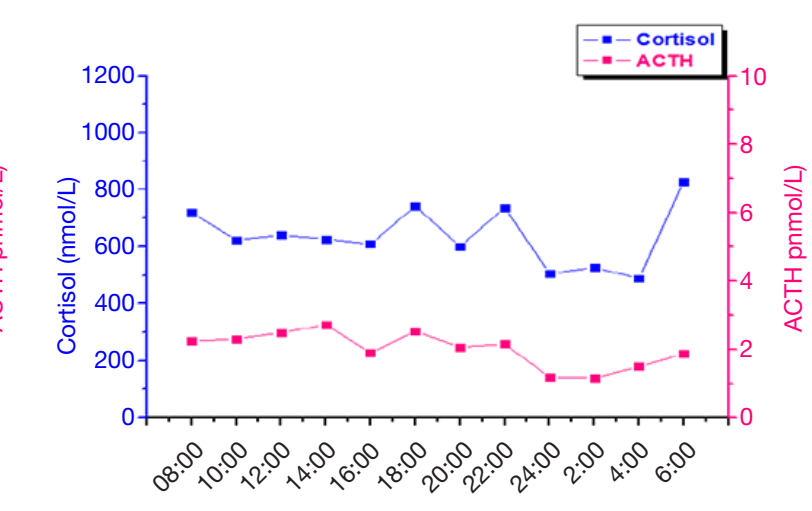

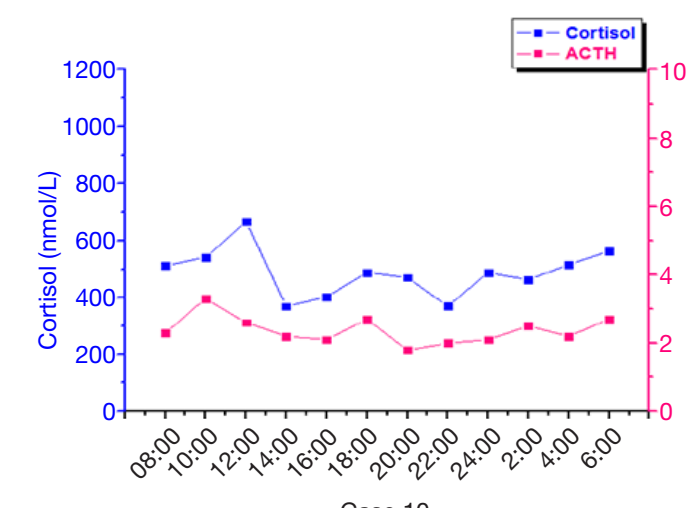

Case 10
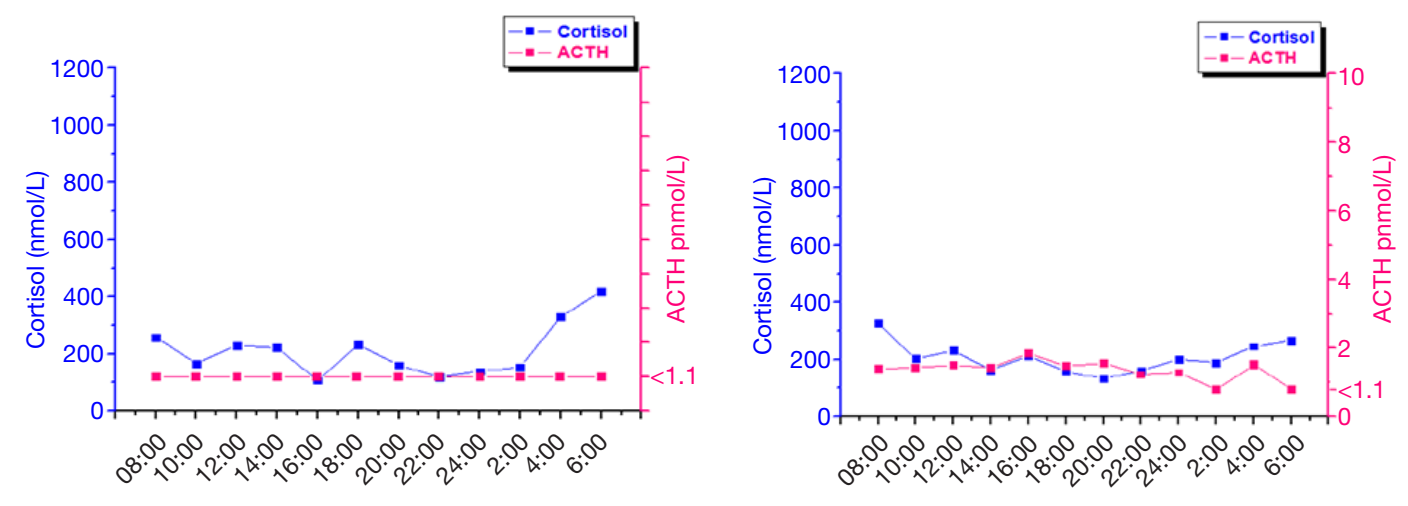

Case 14

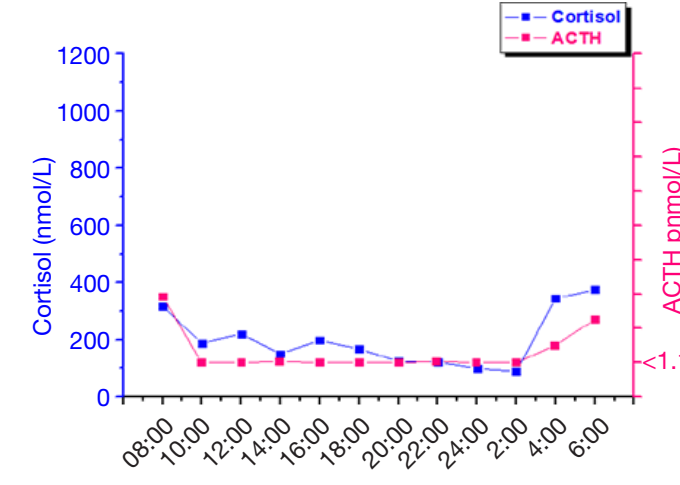

Case 13

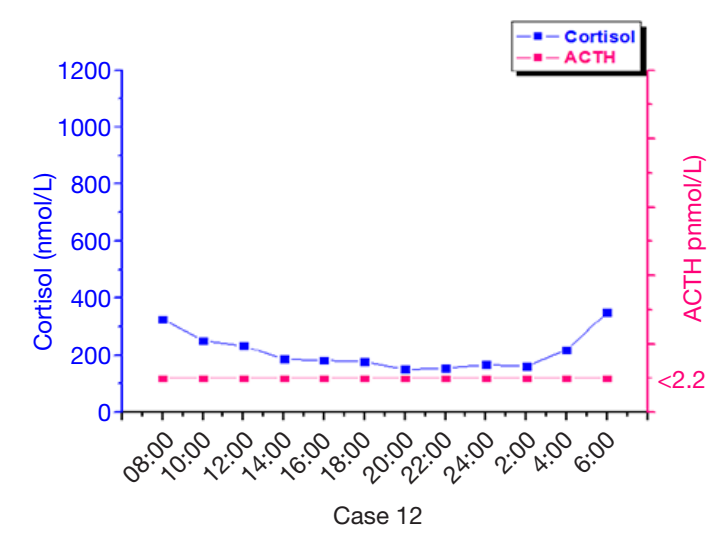

Figure 3 Profiles of 24 hours ACTH and cortisol levels in 14 patients with PBMAH. ACTH, adrenocorticotropic hormone; PBMAH, primary bilateral macronodular adrenal hyperpalsia. 

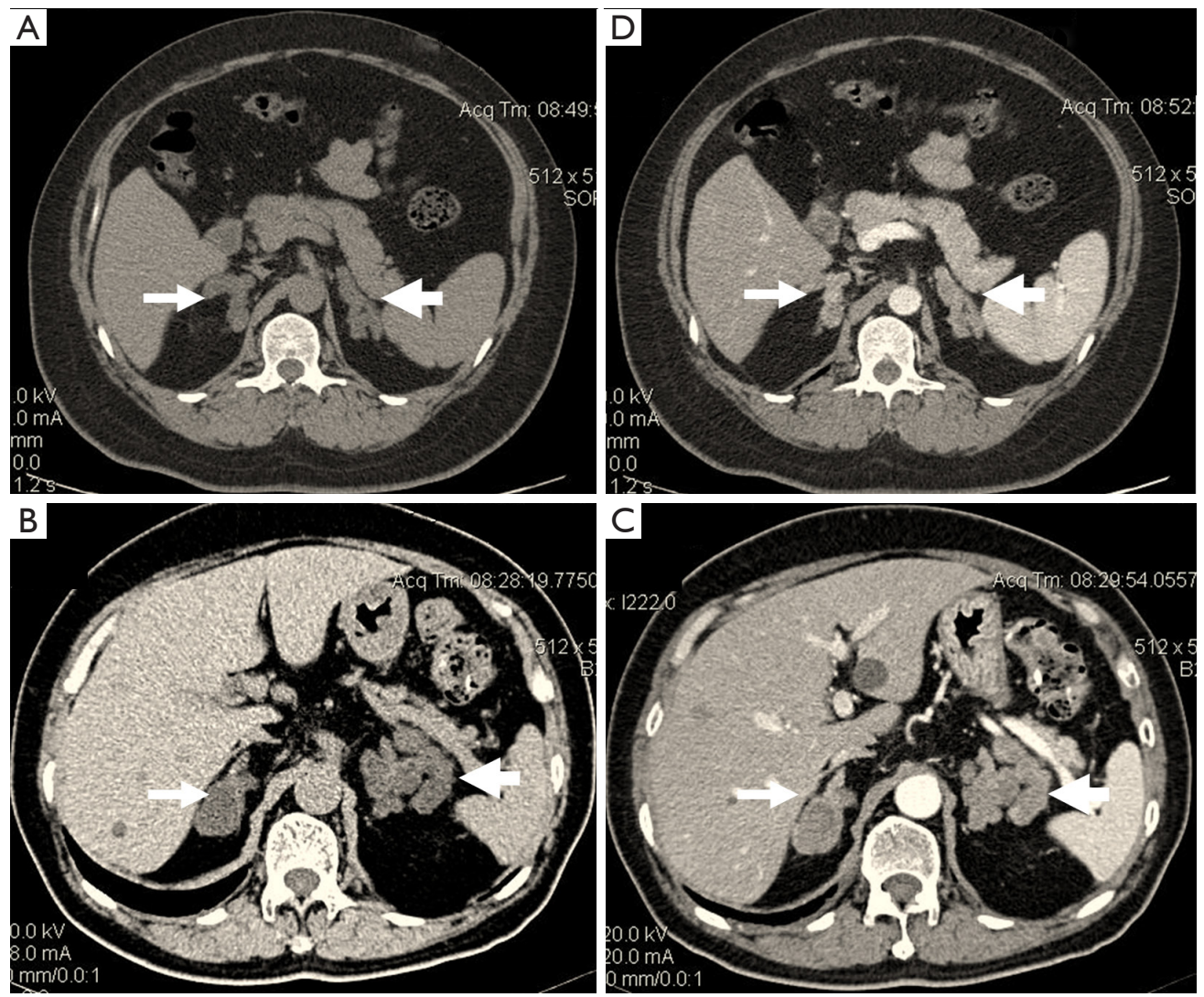

Figure 4 CT image features of PBMAH. (A,B) Most PBMAH patients had adrenal glands with a standard shape. (C,D) Some patients had significant large macronodules that had lost the standard shape of the adrenal gland. Arrows show the adrenal glands. PBMAH, primary bilateral macronodular adrenal hyperplasia.

However, HDDST was suppressed in the Cushing disease group (8). Kuzu et al. determined the diagnostic value of late-night salivary cortisol in diagnosing autonomous cortisol secretion and compared it with 24 hours UFC, which found its levels in subjects with autonomous cortisol secretion were significantly higher than in subjects with non-functioning adrenal adenoma and the control group (9). However, there are few studies conducted in both PBMAH patients and UAA. Our study is clinical, on the most significant number of cases with $\mathrm{PBMAH}$ in China, of great significance for raising awareness of $\mathrm{PBMAH}$ and improving a deeper understanding of the cortisol secretion spectrum of adrenal diseases. In this study, we compared PBMAH patients and unilateral adenoma patients in terms of clinical features and dexamethasone suppression results. The PBMAH patients tend to show mild symptoms of autonomous cortisol secretion and have significantly lower plasma levels of cortisol and 24 hours UFC compared with the unilateral adenoma patients. Also, the PBMAH patients showed much higher responses to dexamethasone suppression than the UAA patients.

In our patients, most PBMAH was accidentally found during their routine health examination. Many of the PBMAH patients were asymptomatic or had mild symptoms of autonomous cortisol secretion, showing that the actual prevalence of $\mathrm{PBMAH}$ might be much higher than it is estimated from the incidental findings. Earlier studies have shown a female dominance in patients with CS, Cushing's disease, and unilateral adrenal adenomas, but a balanced sex ratio in PBMAH patients $(2,10,11)$. PBMAH patients usually present at their 50 to 60 years, often older than those with PPNAD, Cushing's disease, and UAA $(1,2,12,13)$. The time from the first symptoms of PBMAH to the diagnosis can be about 7.8 years (13). In our PBMAH patients, the male to female ratio was $1.3: 1$ with a mean age of 52.1 years and a mean disease course of 6.5 years, which was consistent with earlier findings.

In our study, the PBMAH patients and the UAA patients 


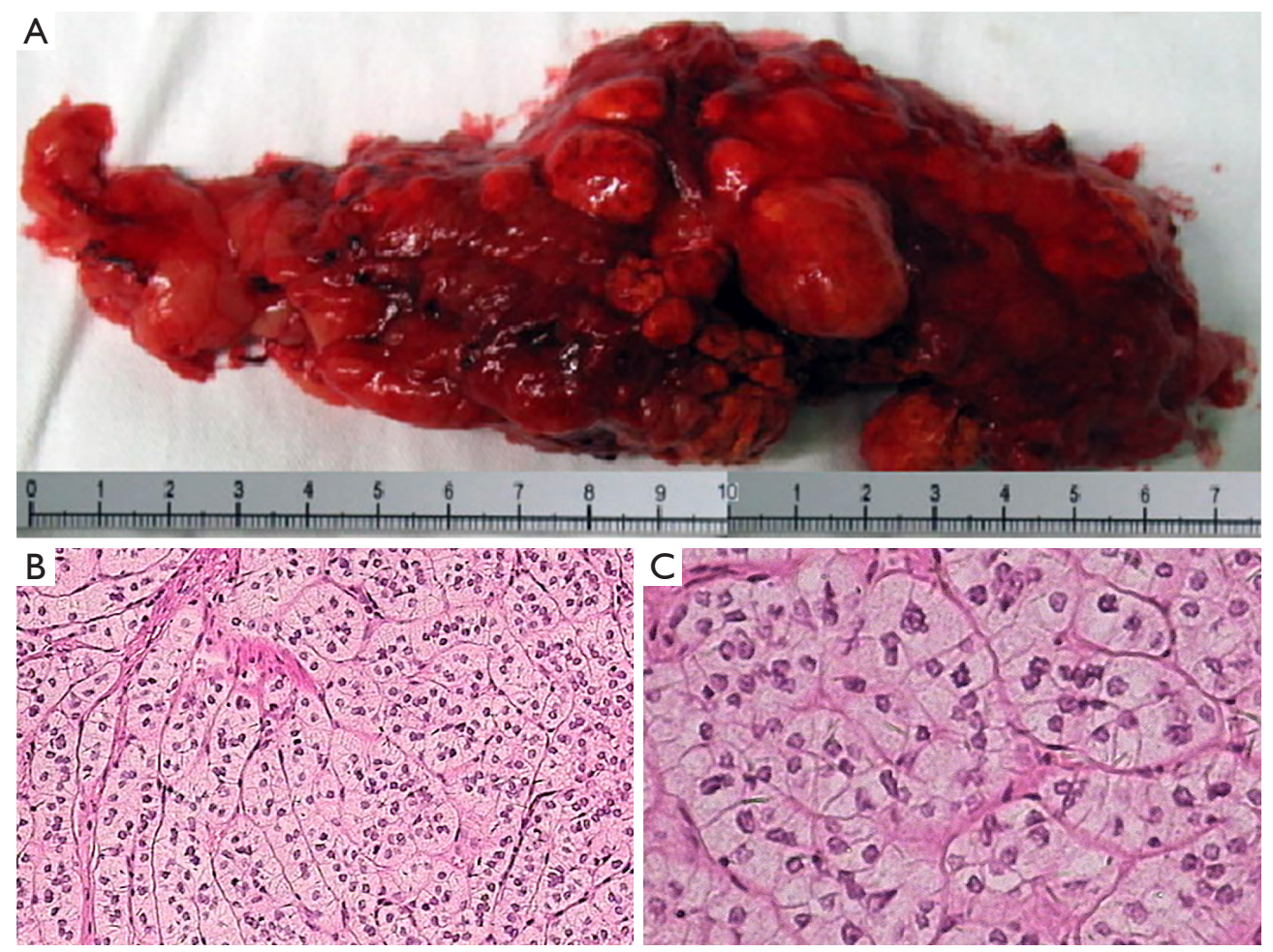

Figure 5 Pathological features of PBMAH. (A) A typical gross view of a resected PBMAH showing macronodular changes. (B) HE staining of the adrenal cortex shows macronodular structures (40x). (C) HE stains of the nodules show transparent cells and eosinophils (100x). PBMAH, primary bilateral macronodular adrenal hyperplasia; HE, hematoxylin and eosin.

Table 3 The clinical data of 10 PBMAH patients treated with unilateral adrenalectomy (part 1)

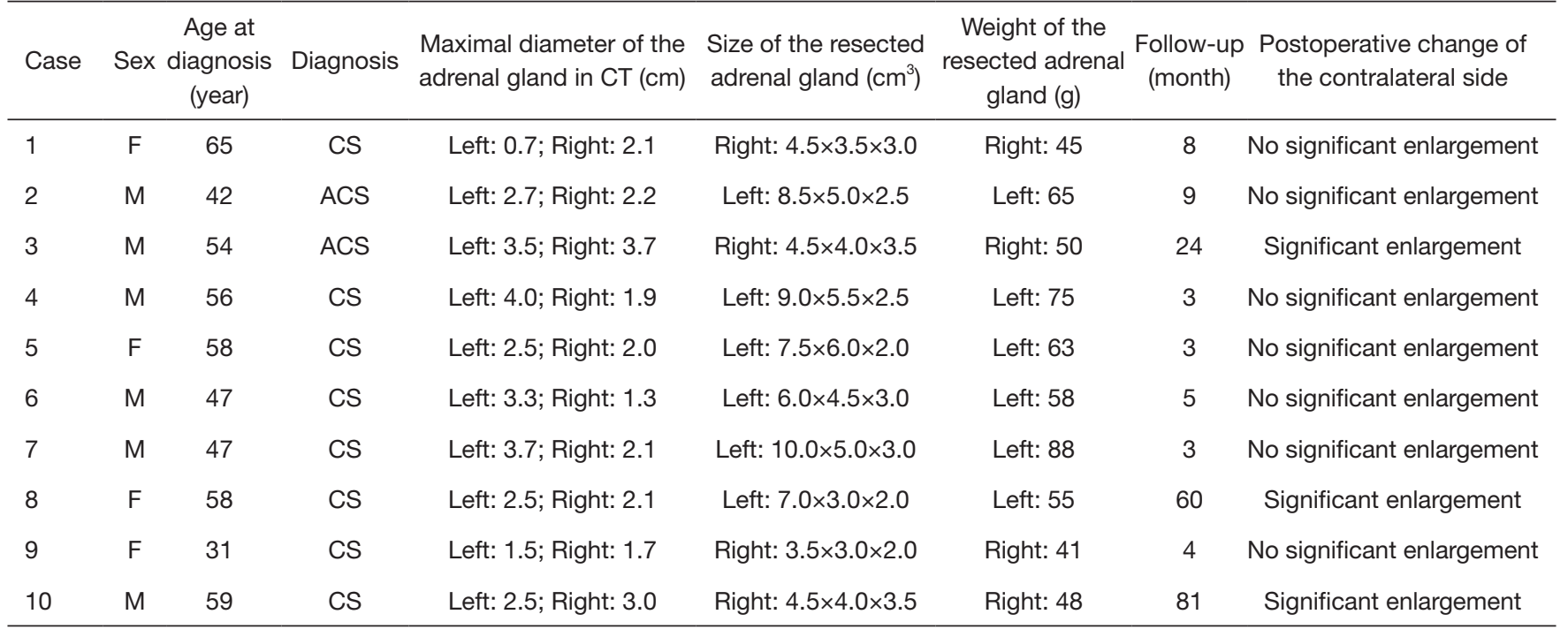

PBMAH, primary bilateral macronodular adrenal hyperplasia; F, female; M, male; CS, Cushing's syndrome; ACS, autonomous cortisol secretion. 


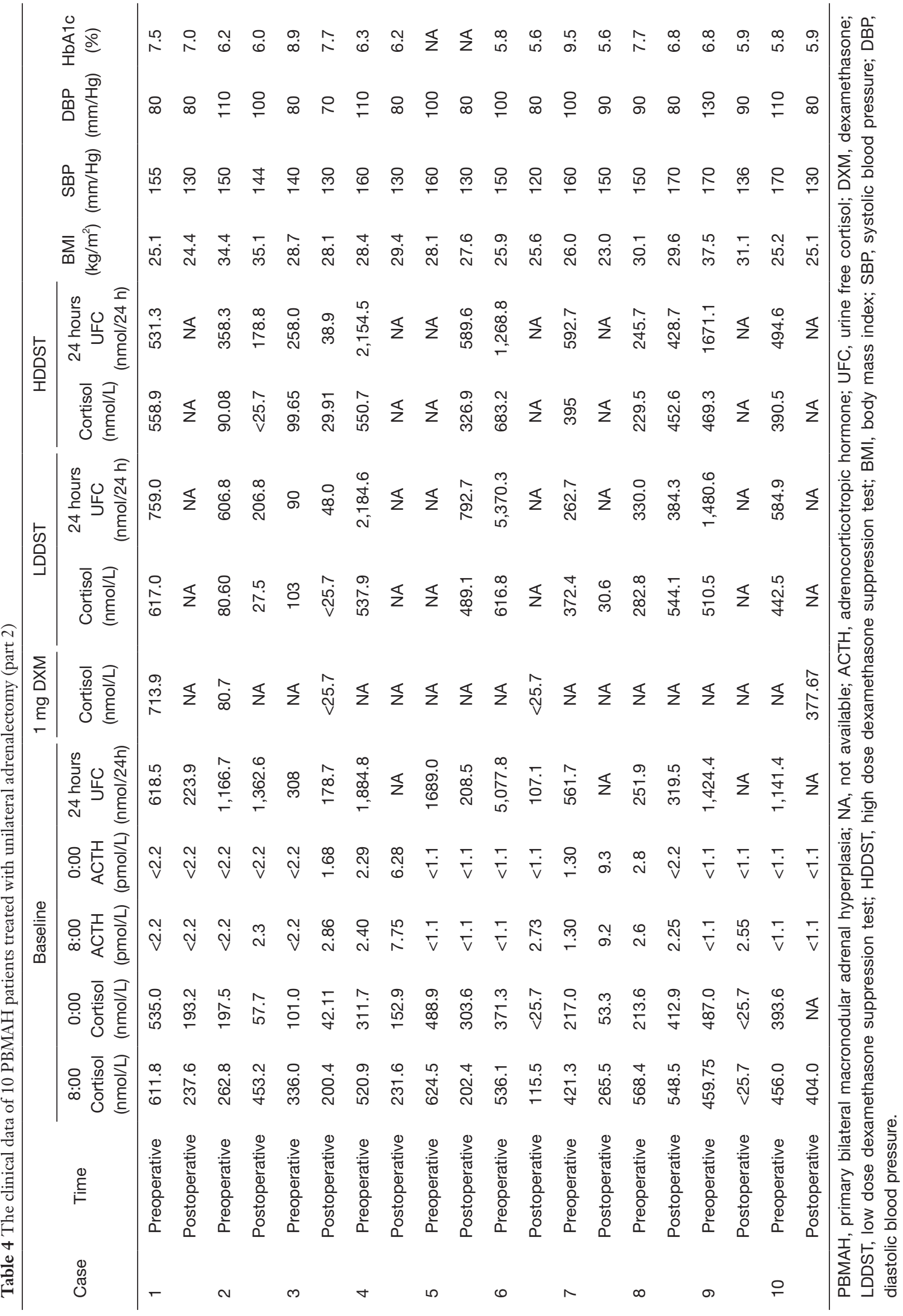


did not differ significantly in the incidence of symptoms including hypertension, hyperglycemia, and hypokalemia. However, the PBMAH patients had significantly lower incidences of moon face and central obesity than the UAA patients, suggesting the atypical CS symptoms in $\mathrm{PBMAH}$ patients. These findings may explain the delayed diagnosis of PBMAH patients. We also found the PBMAH patients had significantly lower levels of cortisol and 24 hours UFC at baseline and during DSTs whereas with the unilateral adenoma patients. Consistently, significantly more PBMAH patients had autonomous cortisol secretion $(39.1 \%)$ than the UAA patients $(6.8 \%)$. These most critical findings show

Table 5 Comparison of the clinical data before and after unilateral adrenalectomy

\begin{tabular}{lcc}
\hline Characteristics & Preoperative & Postoperative \\
\hline Systolic pressure $(\mathrm{mmHg})$ & $155.91 \pm 9.17$ & 130.00 \\
& & $(130.00,144.00)^{\star}$ \\
Diastolic pressure $(\mathrm{mmHg})$ & $100.91 \pm 14.46$ & 80.00 \\
& & $(80.00,90.00)^{\star}$ \\
Body mass index $\left(\mathrm{kg} / \mathrm{m}^{2}\right)$ & 28.10 & $27.77 \pm 3.44$ \\
& $(25.70,30.10)$ & \\
HbA1c $(\%)$ & $7.17 \pm 1.34$ & $6.30 \pm 0.72$ \\
8:00 Cortisol $(\mathrm{nmol} / \mathrm{L})$ & $502.27 \pm 133.79$ & $271.16 \pm 150.13^{*}$ \\
0:00 Cortisol $(\mathrm{nmol} / \mathrm{L})$ & $351.97 \pm 154.81$ & $141.57 \pm 130.93^{*}$ \\
24 hours UFC $(\mathrm{nmol} / 24 \mathrm{~h})$ & $1,160.70$ & 216.20 \\
& $(561.71,1,689.00)$ & $(178.70,319.50)^{\star}$ \\
\hline
\end{tabular}

${ }^{*}, \mathrm{P}<0.05$. UFC, urine free cortisol. that although the adrenal glands of PBMAH present with a marked increase in volume, their ability to secrete cortisol is less active.

The diagnosis of PBMAH should be differentiated from other diseases, also causing bilateral adrenal hyperplasia. Louiset et al. examined the abnormal production of corticotropin in these hyperplastic adrenal glands. They found that cortisol secretion by the adrenals in patients with macronodular hyperplasia and CS is regulated by corticotropin (14). Li et al. presented the treatment observations of patients with PBMAH from a single medical center, and a pointed diagnosis of PBMAH is usually derived from the pathological examination, and unilateral adrenalectomy may achieve long term remission (15). A CT examination is superior to other imaging techniques in showing details of micronodular adrenal lesions, adrenal hyperplasia, and adrenal hypoplasia $(16,17)$. PPNAD is a rare type of CS and is usually found in adolescents. This condition can be sporadic or familial and is often associated with Carney's complex. CT images show normal or slightly enlarged adrenal glands in PPNAD with bilateral "bead-string" micronodular hyperplasia. The nodular diameter in PPNAD is usually less than $4 \mathrm{~mm}$ with pigmentation and intranodular cortex hypertrophy $(18,19)$.

On the contrary, PBMAH shows larger nodular diameters, which range from 0.5 to $3.5 \mathrm{~cm}$ in our study. In Cushing's disease, the bilateral adrenal hyperplasia is ACTH-dependent, and the plasma ACTH levels are elevated. DST is useful in differentiating Cushing's

Table 6 The clinical data of the patients treated with bilateral adrenalectomy (part 1)

\begin{tabular}{|c|c|c|c|c|c|c|c|c|c|}
\hline Case & Sex & $\begin{array}{c}\text { Age at } \\
\text { diagnosis } \\
\text { (year) }\end{array}$ & Diagnosis & $\begin{array}{l}\text { Maximal diameter } \\
\text { of the adrenal } \\
\text { gland in CT }(\mathrm{cm})\end{array}$ & $\begin{array}{l}\text { Size of the resected } \\
\text { adrenal gland }\left(\mathrm{cm}^{3}\right)\end{array}$ & $\begin{array}{l}\text { Weight of } \\
\text { the resected } \\
\text { adrenal } \\
\text { gland }(\mathrm{g})\end{array}$ & $\begin{array}{l}\text { Postoperative hormone } \\
\text { replacement therapy }\end{array}$ & $\begin{array}{l}\text { Follow-up } \\
\text { (months) }\end{array}$ & $\begin{array}{c}\text { CS } \\
\text { symptoms }\end{array}$ \\
\hline 1 & Female & 54 & CS & $\begin{array}{l}\text { Left: } 2.8 \\
\text { Right: } 4.5\end{array}$ & $\begin{array}{l}\text { Left: } 6.0 \times 5.0 \times 5.0 \\
\text { Right: } 7.0 \times 6.0 \times 4.0\end{array}$ & $\begin{array}{l}\text { Left: } 82 \\
\text { Right: } 94\end{array}$ & $\begin{array}{l}\text { Prednisone acetate: } \\
2.5 \mathrm{mg} \text { in the morning } \\
\text { and } 2.5 \mathrm{mg} \text { in the night; } \\
\text { fludrocortisone acetate } \\
0.1 \mathrm{mg} \text { per day }\end{array}$ & ; & $\begin{array}{l}\text { Significantly } \\
\text { relieved }\end{array}$ \\
\hline 2 & Male & 42 & ACS & $\begin{array}{l}\text { Left: } 2.0 \\
\text { Right: } 2.7\end{array}$ & $\begin{array}{l}\text { Left: } 4.5 \times 2.8 \times 1.0 \\
\text { Right: } 5.0 \times 3.0 \times 1.0\end{array}$ & $\begin{array}{l}\text { Left: } 40 \\
\text { Right: } 50\end{array}$ & $\begin{array}{l}\text { Hydrocortisone acetate: } \\
10 \mathrm{mg} \text { in the morning } \\
\text { and } 10 \mathrm{mg} \text { in the night }\end{array}$ & 48 & $\begin{array}{l}\text { Significantly } \\
\text { relieved }\end{array}$ \\
\hline 3 & Female & 57 & CS & $\begin{array}{l}\text { Left: } 2.5 \\
\text { Right: } 2.1\end{array}$ & $\begin{array}{c}\text { Left: } 4.0 \times 2.5 \times 1.8 \\
\text { Right: } 3.8 \times 2.7 \times 1.5\end{array}$ & $\begin{array}{l}\text { Left: } 48 \\
\text { Right: } 40\end{array}$ & $\begin{array}{l}\text { Prednisone acetate } \\
2.5 \mathrm{mg} \text { per day }\end{array}$ & 7 & $\begin{array}{l}\text { Significantly } \\
\text { relieved }\end{array}$ \\
\hline
\end{tabular}

CS, Cushing's syndrome; ACS, autonomous cortisol secretion. 


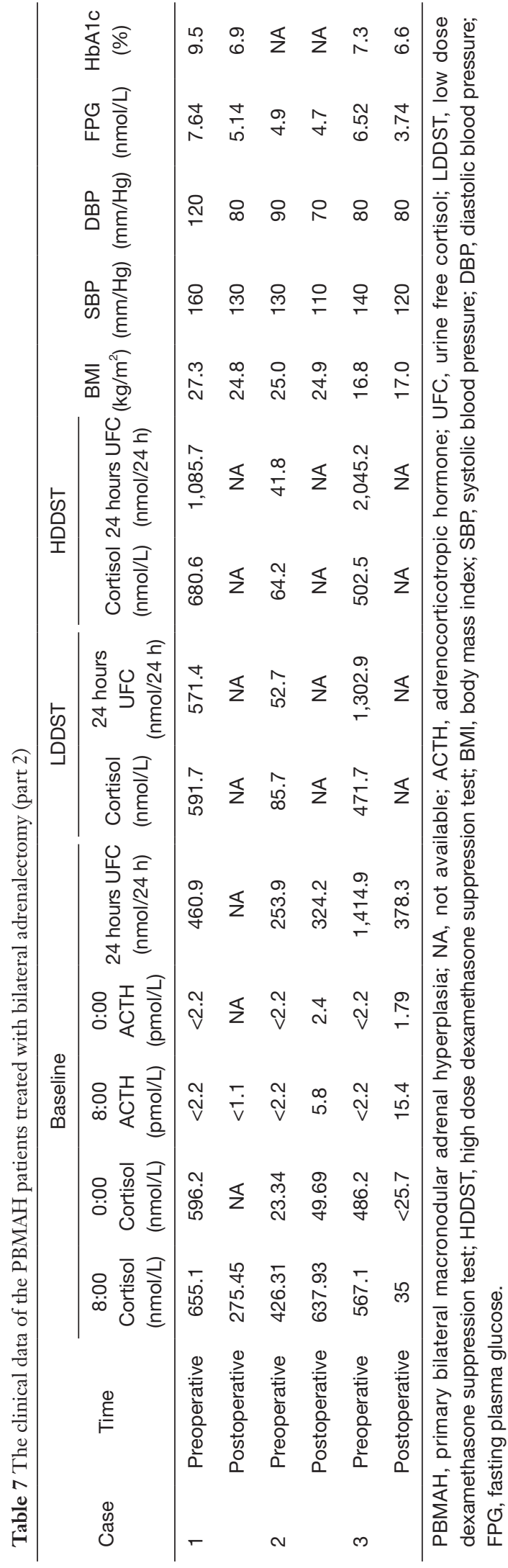

disease and PBMAH (1). Primary aldosteronism and pheochromocytoma can also cause bilateral adrenal hyperplasia but lack the excessive cortisol production, which is distinct from PBMAH.

In conclusion, PBMAH is a rare condition and is often associated with atypical autonomous cortisol secretion symptoms, a significant challenge for prompt diagnosis. Many patients were incidentally found with bilateral adrenal macronodular hyperplasia and further diagnosed with $\mathrm{PBMAH}$, suggesting that the actual prevalence of this condition may be much higher. PBMAH patients have significantly lower levels of cortisol and 24 hours UFC at baseline and during DSTs yet with the UAA patients. The clinical and imaging features of PBMAH are useful for the differential diagnosis of this disease.

\section{Acknowledgments}

Funding: The Hainan Provincial Natural Science Foundation for Young Scholars in China (Approval number: 819QN374) supported this study.

\section{Footnote}

Reporting Checklist: The authors have completed the MDAR reporting checklist. Available at http://dx.doi.org/10.21037/ atm-20-5963

Data Sharing Statement: Available at http://dx.doi. org/10.21037/atm-20-5963

Conflicts of Interest: All authors have completed the ICMJE uniform disclosure form (available at http://dx.doi. org/10.21037/atm-20-5963). The authors have no conflicts of interest to declare.

Ethical Statement: The authors are accountable for all aspects of the work in ensuring that questions related to the accuracy or integrity of any part of the work are appropriately investigated and resolved. The ethics committee of our hospital approved this study (No. 2020062). Informed consent was obtained from all the patients. All procedures performed in this study involving human participants were in accordance with the Declaration of Helsinki (as revised in 2013).

Open Access Statement: This is an Open Access article distributed in accordance with the Creative Commons 
Attribution-NonCommercial-NoDerivs 4.0 International License (CC BY-NC-ND 4.0), which permits the noncommercial replication and distribution of the article with the strict proviso that no changes or edits are made and the original work is properly cited (including links to both the formal publication through the relevant DOI and the license). See: https://creativecommons.org/licenses/by-nc-nd/4.0/.

\section{References}

1. Lin W, Huang HB, Wen JP, et al. Approach to Cushing's syndrome in pregnancy: two cases of Cushing's syndrome in pregnancy and a review of the literature. Ann Transl Med 2019;7:490.

2. Lacroix A, Ndiaye N, Tremblay J, et al. Ectopic and abnormal hormone receptors in adrenal Cushing's syndrome. Endocr Rev 2001;22:75-110.

3. Swain JM, Grant CS, Schlinkert RT, et al. Corticotropinindependent macronodular adrenal hyperplasia: a clinicopathologic correlation. Arch Surg 1998;133:541-5; discussion 545-6.

4. Doppman JL. Problems in endocrinologic imaging. Endocrinol Metab Clin North Am 1997;26:973-91.

5. De Venanzi A, Alencar GA, Bourdeau I, et al. Primary bilateral macronodular adrenal hyperplasia. Curr Opin Endocrinol Diabetes Obes 2014;21:177-84.

6. Assié G, Libé R, Espiard S, et al. ARMC5 mutations in macronodular adrenal hyperplasia with Cushing's syndrome. N Engl J Med 2013;369:2105-14.

7. Lacroix A. Heredity and cortisol regulation in bilateral macronodular adrenal hyperplasia. N Engl J Med 2013;369:2147-9.

8. Zhang Y, Li H. Classification and surgical treatment for 180 cases of adrenocortical hyperplastic disease. Int J Clin Exp Med 2015;8:19311-7.

9. Kuzu I, Zuhur SS, Demir N, et al. The diagnostic value of late-night salivary cortisol for diagnosis of subclinical Cushing's syndrome. Endokrynol Pol 2016;67:487-92.

10. Lacroix A, Tremblay J, Rousseau G, et al. Propranolol

Cite this article as: Zhang Q, Xiao H, Han S, Li Y, Chen K, Zang L, Du J, Wang X, Guo Q, Yang G, Ba J, Gu W, Lyu Z, Dou J, Mu Y, Lu J. Analysis of clinical and pathological features of primary bilateral macronodular adrenocortical hyperplasia compared with unilateral cortisol-secreting adrenal adenoma. Ann Transl Med 2020;8(18):1173. doi: 10.21037/atm$20-5963$ therapy for ectopic beta-adrenergic receptors in adrenal Cushing's syndrome. N Engl J Med 1997;337:1429-34.

11. Lieberman SA, Eccleshall TR, Feldman D. ACTHindependent massive bilateral adrenal disease (AIMBAD): a subtype of Cushing's syndrome with major diagnostic and therapeutic implications. Eur J Endocrinol 1994;131:67-73.

12. Stratakis CA, Kirschner LS. Clinical and genetic analysis of primary bilateral adrenal diseases (micro- and macronodular disease) leading to Cushing syndrome. Horm Metab Res 1998;30:456-63.

13. Zeiger MA, Nieman LK, Cutler GB, et al. Primary bilateral adrenocortical causes of Cushing's syndrome. Surgery 1991;110:1106-15.

14. Louiset E, Duparc C, Young J, et al. Intra-adrenal corticotropin in bilateral macronodular adrenal hyperplasia. N Engl J Med 2013;369:2115-25.

15. Li J, Yang CH. Diagnosis and treatment of adrenocorticotrophic hormone-independent macronodular adrenocortical hyperplasia: A report of 23 cases in a single center. Exp Ther Med 2015;9:507-12.

16. Lacroix A. ACTH-independent macronodular adrenal hyperplasia. Best Pract Res Clin Endocrinol Metab 2009;23:245-59.

17. Doppman JL, Chrousos GP, Papanicolaou DA, et al. Adrenocorticotropin-independent macronodular adrenal hyperplasia: an uncommon cause of primary adrenal hypercortisolism. Radiology 2000;216:797-802.

18. Horvath A, Stratakis C. Primary pigmented nodular adrenocortical disease and Cushing's syndrome. Arq Bras Endocrinol Metabol 2007;51:1238-44.

19. Tung SC, Hwang DY, Yang JW, et al. An unusual presentation of Carney complex with diffuse primary pigmented nodular adrenocortical disease on one adrenal gland and a nonpigmented adrenocortical adenoma and focal primary pigmented nodular adrenocortical disease on the other. Endocr J 2012;59:823-30.

(English Language Editor: J. Chapnick) 